\title{
ANALISIS SIFAT TERMAL DAN UJI KELARUTAN DARI KARET ALAM SIKLIS DAN KARET ALAM CAIR SIKLIS
}

\section{ANALYSIS OF THERMAL PROPERTIES AND SOLUBILITY TEST OF CYCLIC NATURAL RUBBER AND CYCLIC LIQUID NATURAL RUBBER}

\author{
Leni Widiarti" ${ }^{*}$, Basuki Wirjosentono ${ }^{1}$, dan Eddyanto ${ }^{2}$ \\ ${ }^{1}$ Department of Chemistry, Faculty of Mathematics and Natural Sciences, \\ University of Sumatera Utara, Medan, Indonesia \\ ${ }^{2}$ Department of Chemistry, Faculty of Mathematics and Natural Sciences, University State of Medan, Medan, Indonesia \\ *Coresponding Author: Lwidhii@gmail.com
}

Submit : 19 Mei 2017 Accepted : 23 Februari 2018

\begin{abstract}
The research has done analysis of thermal properties and solubility test of Cyclic Natural Rubber (CNR) and Cyclic Liquid Natural Rubber (CLNR). Cyclic Liquid Natural Rubber (CLNR) is a cyclical natural rubber which has decreased molecular weight. Synthesis of Cyclic Liquid Natural Rubber (CLNR) do by oxidative degradation after cyclic. Oxidative degradation after cyclic using Cyclic Natural Rubber (CNR) and phenylhydrazine reagent with flow rate 2 LMin- 1 of oxygen atmosphere during 24 hours. Thermal analysis of Cyclic Natural Rubber (CNR) and Cyclic Liquid Natural Rubber (CLNR) by Differential Scanning Calorimetry (DSC), the glass transition temperature (Tg) of Cyclic Natural Rubber (CNR) and Cyclic Liquid Natural Rubber (CLNR) are 102,82 ${ }^{\circ} \mathrm{C}$ and $103,67{ }^{\circ} \mathrm{C}$, the crystal transition temperature (Tc) of Cyclic Natural Rubber (CNR) and Cyclic Liquid Natural Rubber (CLNR) are 362,45 ${ }^{\circ} \mathrm{C}$ and $330,29{ }^{\circ} \mathrm{C}$ and the melting transition temperature ( $\mathrm{Tm}$ ) of Cyclic Natural Rubber (CNR) and Cyclic Liquid Natural Rubber (CLNR) are 509,24 ${ }^{\circ} \mathrm{C}$ and $440,00{ }^{\circ} \mathrm{C}$. Solubility test by dilute Cyclic Natural Rubber (CNR) and Cyclic Liquid Natural Rubber (CLNR) in some solvent with different properties and polarity index. Solubility test shows the results Cyclic Natural Rubber (CNR) and Cyclic Liquid Natural Rubber (CLNR) has polarity index around 2,4-4,4 and 2,4 and 4,4.
\end{abstract}

Keywords: CLNR, CNR, oxidative degradation.

\section{PENDAHULUAN}

Resiprene 35 adalah resin karet siklisasi yang berasal dari karet alam dan memiliki viskositas yang relatif tinggi. Resiprene 35 dipasok sebagai solid pasir dan juga dalam larutan aromatik [1]. Bobot molekul karet alam yang tinggi disebabkan oleh rantai molekulnya yang panjang. Bobot molekul mempengaruhi sifat-sifat polimer seperti kelarutan, kerekatan, ketercetakan dan kekentalan. Sifat karet alam ini akan mempengaruhi kemampuan pemrosesan karet. Bobot molekul karet alam yang tinggi ini membatasi penggunaan karet alam dalam dunia industri. Depolimerisasi merupakan salah satu cara modifikasi karet alam dengan cara degradasi rantai molekul karet. Degradasi polimer dapat terjadi secara mekanis, termal, kimiawi, fotokimia, dan biodegradasi. Secara kimiawi degradasi polimer dapat terjadi dengan bantuan senyawa pemutus rantai molekul polimer. Tujuan depolimerisasi adalah untuk melunakkan atau sekedar menurunkan viskositas karet, dan untuk memperoleh karet dengan rantai molekul yang sangat pendek atau karet cair [2]. Beberapa metode dapat digunakan untuk memutus rantai molekul NR. Salah satu proses yang paling ekonomis menggunakan phenylhydrazine dan oksigen atmosfer dan dikembangkan oleh seorang peneliti Perancis [3]. Depolimerisasi dari NR dilakukan dengan lateks NR dan berat molekul dikontrol oleh perbandingan phenylhydrazine. Ini dipahami disebabkan oleh reaksi langsung dari phenylhydrazine dengan oksigen, membentuk radikal fenil [4]. Metode pengurangan bobot molekul karet alam dapat dilakukan dengan menggunakan agensia pengoksidasi (udara, oksigen atau suatu peroksida) dan agensia pereduksi (suatu nitrit logam dan/atau suatu klorit logam) [5]. Degradasi lateks karet alam dengan tert-butyl hydroperoxide dan cobalt acetylacetonate juga berhasil menurunkan bobot molekul karet dan diperoleh karet alam cair. Fungsionalisasi karet juga terjadi yaitu dengan terbentuknya gugus fungsi keton dan karboksilat 
pada ujung rantai molekul karet [6]. Tingginya bobot molekul karet alam menjadikan barang jadi karet kalah bersaing dengan resin dan karet sintetik yang lain. Pada pembuatan barang jadi karet maupun penggunaan pada formulasi dengan polimer yang lain dibutuhkan karet alam dengan bobot molekul yang lebih rendah agar dapat digunakan lebih efektif, jadi peneliti ingin melakukan sintesis karet alam cair siklis dengan berat molekul rendah dengan harapan menjadi salah satu jalan keluar untuk meningkatkan kualitas karet alam sebagai salah satu komoditi terbesar di Indonesia dan meningkatkan daya saing terhadap resin dan karet sintesis.

\section{METODE PENELITIAN}

\section{Pembuatan Cyclic Liquid Natural Rubber (CLNR)}

Untuk membuat Cyclic Liquid Natural Rubber (CLNR) dapat menggunakan metode degradasi oksidatif (Metode Brosse). Dimasukkan 50 gram karet CNR kedalam beaker glass, dilarutkan dengan xylene hingga larut seluruhnya. Dimasukkan larutan yang telah larut kedalam labu leher tiga yang kemudian dirangkai alat labu leher tiga terhubung dengan regulator gas $\mathrm{O}_{2}$ melalui selang gas, dan digantungkan termometer $100{ }^{\circ} \mathrm{C}$ yang telah terhubung kedalam labu leher tiga, ditutup dengan alumunium foil secara menyeluruh labu leher tiga serta dipanaskan dengan menggunakan hot plate sampai suhunya mencapai $60{ }^{\circ} \mathrm{C}$ serta selanjutnya ditambahkan phenylhydrazine setetes demi setetes sebanyak $25,31 \mathrm{~g}$ dan dialirkan gas $\mathrm{O}_{2}$ kedalam campuran tersebut dengan laju alir $2 \mathrm{~L} /$ menit dan distirer pada suhu $60^{\circ} \mathrm{C}$ selama 24 jam.

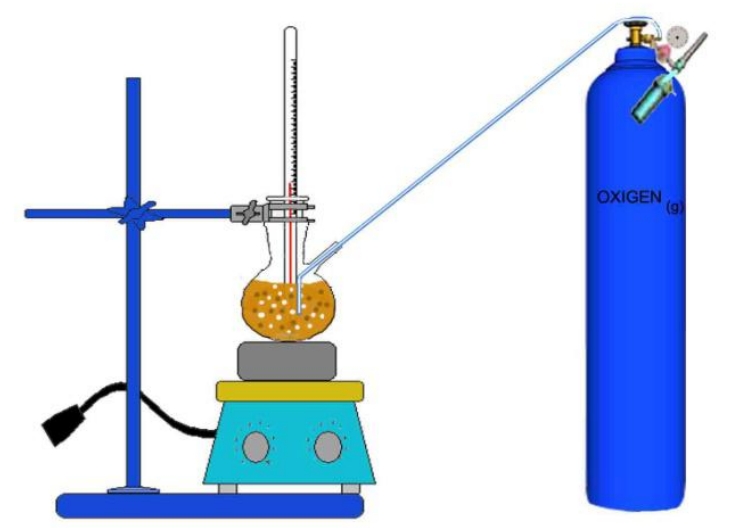

Gambar 1. Skema Alat Pembuatan Cyclic Liquid Natural Rubber (CLNR)

CLNR yang diperoleh presipitasi dengan methanol sebanyak $1,25 \mathrm{~L}$ dan dikeringkan didalam oven pada suhu $40{ }^{\circ} \mathrm{C}$ sampai beratnya konstan. CLNR yang dihasilkan dikarakterisasi dengan menggunakan analisa termal Differential Scanning Calorimetry (DSC) dan uji kelarutan dengan beberapa pelarut organik.

\section{HASIL DAN PEMBAHASAN \\ Pembuatan Cyclic Liquid Natural Rubber (CLNR)}

CLNR yang dihasilkan berwarna kuning kecoklatan dan lengket.

\section{Pengujian Sifat Termal dengan DSC}

Prinsip DSC tidak jauh berbeda dengan prinsip kalorimetri biasa, hanya dalam hal ini digunakan sampel dari polimer yang agak jauh lebih kecil (maksimum $50 \mathrm{mg}$, misalnya $10 \mathrm{mg}$ ) dan peralatan kalor lebih teliti). Hasil pengujian DSC merupakan kurva termogram yang dapat digunakan untuk menentukan suhu transisi glass dan suhu leleh. Dalam polimer kristal, rantai polimer yang diberikan ada di atau melewati beberapa zona kristal dan amorf. Zona kristal terdiri dari keselarasan antarmolekul dan intramolekul atau susunan yang teratur dan karenanya erat dikemas molekul atau segmen rantai, dan kurangnya hasil dalam pembentukan zona amorf. Atas dasar berikut perubahan parameter sifat mekanik seperti modulus geser dengan perubahan (kenaikan) dalam suhu pengamatan untuk sistem bahan polimer, dapat diamati berturut-turut yaitu transisi gelas dan fenomena transisi leleh, lebih mudah dari plot grafis, dan juga mungkin memiliki ukuran suhu transisi gelas (Tg) dan suhu leleh (Tm) [7]. Temperatur transisi gelas (Tg) merupakan salah satu sifat fisik penting dari polimer yang menyebabkan polimer tersebut memiliki daya tahan terhadap panas atau suhu yang berbeda-beda. Dimana pada saat temperatur luar mendekati temperatur transisi gelasnya maka suatu polimer mengalami perubahan dari keadaan yang keras kaku menjadi lunak seperti karet. adanya perbedaan Tg ini disebabkan oleh berbagai faktor yang meliputi panjang molekul polimer, berat molekul polimer, efek elektrostatik seperti polarisabilitas, momen dwi kutub, stereokimia dan stereoregularitas rantai polimer maupun interaksi intermolekuler dari polimer melalui ikatan hidrogen dan gaya London. Tidak semua polimer memiliki titik leleh kristal karena tidak akan ada titik leleh kristal bila tidak mempunyai kristalinitas. Titik leleh adalah suhu dimana zat padat berubah menjadi zat cair pada tekanan satu atmosfer. Dengan kata lain, titik leleh merupakan 
suhu ketika fase padat dan cair sama - sama

berada dalam kesetimbangan [8].

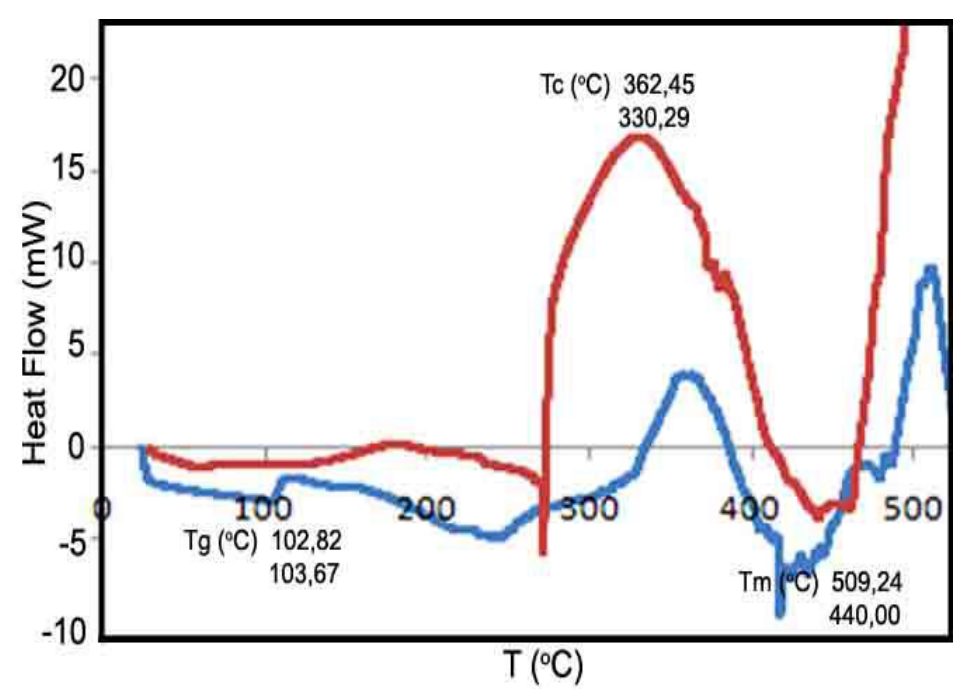

Gambar 2. Termogram DSC dari CNR dan CLNR

Dapat dilihat pada gambar 2. CNR dan CLNR memiliki $\mathrm{Tg}$ masing - masing sebesar $362,45{ }^{\circ} \mathrm{C}$ dan $330,29^{\circ} \mathrm{C}$ dan $\mathrm{Tm}$ masing - masing sebesar $509,24^{\circ} \mathrm{C}$ dan $440,00{ }^{\circ} \mathrm{C}$.

\section{Uji Kelarutan dalam Beberapa Pelarut Organik}

Penentuan uji kelarutan pada senyawa organik dapat dilakukan, diantaranya sejumlah bahan atau material yang ingin digunakan untuk menguji kelarutan sampel organik begitu sederhana yaitu dengan menggunakan 2-3 tetes suatu larutan (zat cair) atau kurang lebih $10 \mathrm{mg}$ sampel zat padat.

Berdasarkan gambar 3 kelarutan dari sampel LNR dapat dilihat berdasarkan prinsip "like dissolves like", dimana senyawa polar dapat larut dalam pelarut polar dan senyawa non polar dapat larut dalam pelarut non polar [9]. Tabel 1 Menunjukkan kelarutan CNR dan CLNR pada beberapa pelarut organik dengan berbagai indeks kepolaran.

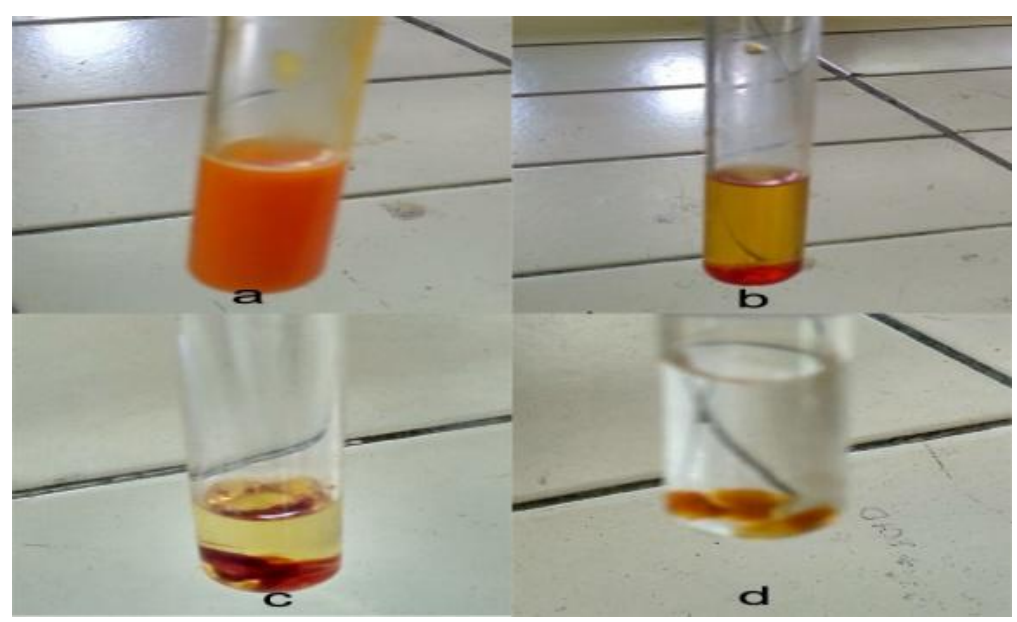

Gambar 3. Ukuran Kelarutan Suatu Sampel CNR dan CLNR (a) Sangat Larut, (b) Larut, (c) Sedikit Larut, (d) Tidak Larut. 
Tabel 1. Kelarutan CNR dan CLNR pada berbagai pelarut organik.

\begin{tabular}{lccc}
\hline Pelarut & $\begin{array}{c}\text { Indeks } \\
\text { Kepolaran }\end{array}$ & CNR & CLNR \\
\hline Air & 10,2 & $\mathrm{TL}$ & $\mathrm{TL}$ \\
Metanol & 6,6 & $\mathrm{TL}$ & $\mathrm{TL}$ \\
Aseton & 5,4 & $\mathrm{TL}$ & $\mathrm{TL}$ \\
Etanol & 5,2 & $\mathrm{TL}$ & $\mathrm{TL}$ \\
Kloroform & 4,4 & $\mathrm{~L}$ & $\mathrm{~L}$ \\
THF & 4,2 & $\mathrm{SL}$ & $\mathrm{L}$ \\
Xilena & 2,5 & $\mathrm{SL}$ & $\mathrm{SL}$ \\
Toluena & 2,4 & $\mathrm{SL}$ & $\mathrm{SL}$ \\
N- Heksana & 0,1 & $\mathrm{SeL}$ & $\mathrm{SeL}$ \\
Sikloheksana & 0,04 & $\mathrm{SeL}$ & $\mathrm{SeL}$ \\
\hline gan : TL = Tidak Larut, SeL $=$ Sedikit Larut, L = Larut, dan SL $=$ Sangat Larut
\end{tabular}

Dari Tabel 1 juga dapat diambil kesimpulan CNR dan CLNR memiliki indeks kepolaran dari 2,4 4,4 dan $2,4-4,4$.

\section{KESIMPULAN}

Cyclic Liquid Natural Rubber (CLNR) berhasil disintesis melalui degradasi oksidatif (Metode Brosse). Degradasi setelah siklisasi menggunakan bahan baku Cyclic Natural Rubber (CNR), degradasi dilakukan dengan bantuan reagen phenylhidrazine dengan suasana gas oksigen dengan laju alir 2 LMenit $^{-1}$ selama 24 jam. Dari hasil analisa termal Cyclic Natural Rubber (CNR) ke Cyclic Liquid Natural Rubber (CLNR) dengan Differential Scanning Clorimetry (DSC) menunjukkan ada sedikit perubahan suhu transisi gelas $(\mathrm{Tg})$ yang signifikan dari yaitu dari $102,82^{\circ}$ C ke 103,67 o C, suhu transisi Kristal (Tc) mengalami penurunan suhu yaitu dari $362,45^{\circ} \mathrm{C}$ ke $330,29{ }^{\circ} \mathrm{C}$ dan dan suhu transisi leleh (Tm) mengalami penurunan yang cukup signifikan yaitu dari $509,24{ }^{\circ} \mathrm{C}$ ke $440,00{ }^{\circ} \mathrm{C}$. Dari uji kelarutan menunjukkan bahwa Cyclic Liquid Natural Rubber (CLNR) sangat larut dalam THF dibandingkan dengan Cyclic Natural Rubber (CNR). Ini menunjukkan bahwa penurunan berat molekul dengan degradasi oksidatif dapat meningkatkan kelarutan dalam pelarut organik.

\section{UCAPAN TERIMA KASIH}

Peneliti mengucapkan terima kasih kepada Lembaga Pengelolaan Dana Pendidikan (LPDP), Industri Karet Nusantara (IKN), dan Laboratorium Kimia Fisika Universitas Sumatera Utara.

\section{DAFTAR PUSTAKA}

[1] Muthawali, D.I. (2013). Optimasi Penggunaan Ammonium Hidroksida Terhadap Mutu Produk Resin Di Pabrik Resiprene. Universitas Sumatera Utara

[2] Fainleib A., Pires R. V., Lucas E. F., Soares B. G., 2013. Degradation of Non-Vulcanized Natural Rubber-Renewable Resources for Fine Chemicals Used in Polymer Synthesis. Polimeros Journal. 1 : 12

[3] Pautrat, R. (1980). Liquid rubbers from natural polyisoprene: preparation and properties [Caoutchoucs liquides de polyisoprene naturel preparation et propriétés]. Revue generale du caoutchouc et des plastiques. $57: 91$

[4] Brosse, (2000). Chemical Modifications of Polydiene Elastomers: A Survey and Some Recent Results. France : Faculte' des Sciences, Universite' du Maine.

[5] Gazeley K. F., Mente P. G., 1996. Metoda Penurunan Berat Molekul Karet di dalam Lateks. Paten Indonesia, ID 0000771.

[6] Klaichim, W., Klinpituksa, P., Waehamad, W., 2009. A Novel Polymeric Herbicide Based on Phenoxyaceic Acid Derivatives, Journal of Science and Technology. 31(1): 57

[7] Ghost, P. 2006. Thermal Transitions in Polymers. Polymer Science

[8] Steven, M.P. 2001. Kimia Polimer. Edisi Pertama. Pradnya Pramita. Yogyakarta

[9] Yazid, E. 2005. Kimia Fisika untuk Paramedis. Yogyakarta : Penerbit ANDI. 